\title{
Las mujeres en la agenda pública: ampliación de derechos y búsqueda de equidad. Argentina (2003-2020)
}

\author{
Women on the Public Agenda: Expanding Rights and the Search for \\ Equity. Argentina (2003-2020)
}

\section{Magali Katz', Gimena Rojo² y María M. Saenz Valenzuela ${ }^{3}$}

\section{Revista \\ Educación y Sociedad}

\section{Citar como: Katz, M., Rojo, G. y Saenz Valenzuela, M. M. (2021). Las mujeres en la agenda pública: ampliación de derechos y búsqueda de equidad. Argentina (2003-2020). Revista Educación y Sociedad, 2(4), 35-47. https://doi.org/10.53940/reys.v2i4.73}

Artículo recibido: 12-08-2021 Artículo aprobado: 26-10-2021 Arbitrado por pares

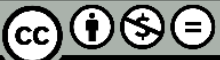

\section{ACEES}

\section{Resumen}

El presente artículo propone analizar el marco normativo existente, enfocando la mirada en las mujeres, y las políticas públicas que a ellas son destinadas. El período 20032020 remite a uno de los avances en políticas sociales y ampliación de derechos. Comenzar en 2003 refiere a la conformación de un nuevo proyecto político, donde se destaca la inclusión social, la recuperación del mercado de trabajo, la generación de empleo (en cantidad y calidad) y, lo que este trabajo busca destacar; ampliación de derechos para las mujeres a través de leyes y programas con mirada transversal y multidimensional (salud, sexualidad, educación, violencia).

Palabras clave: mujeres, leyes, agenda pública, transversalidad

\section{Abstract}

This article proposes to analyze the existing regulatory framework, focusing on women, and the public policies that are intended for them. The period 2003-2020 refers to one of progress in social policies and expansion of rights. Beginning in 2003 refers to the formation of a new political project, which highlights social inclusion, the recovery of the job market, the generation of employment (in quantity and quality) and, what this paper seeks to highlight; expansion of rights for women through laws and programs with a transversal and multidimensional perspective (health, sexuality, education, violence).

Key words: women, law, public agenda, transversely

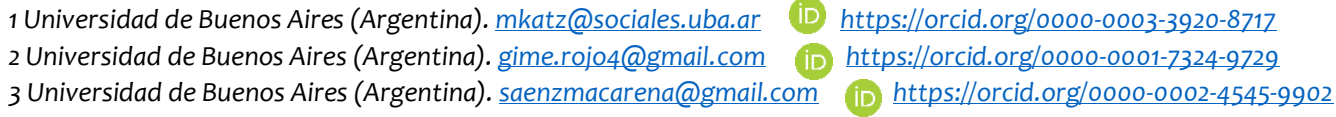




\section{Introducción}

En Argentina, con la vuelta a la democracia en 1983, el movimiento de mujeres ha tomado relevancia. Según Di Marco (2010), se trajo a la arena pública los derechos de las mujeres al denunciar la violencia de género, la doble o triple jornada de trabajo, la falta de políticas de salud sexual y reproductiva, la discriminación laboral, entre otras. Según la autora, el movimiento constó de 3 vertientes: la participación de movimientos de derechos humanos [madres y abuelas], las acciones colectivas de las mujeres de los sectores populares (que se organizaron para enfrentar las duras condiciones de vida, especialmente después de los ajustes) y las mujeres del movimiento feminista ${ }^{1}$ con un fuerte componente en sus orígenes y estabilización de mujeres de sectores medios.

A partir de aquí, según Pecheny (2014), el lenguaje de los Derechos Humanos tomó fuerte relevancia ya que permitía impugnar las atrocidades de la dictadura y funcionaba como base para la renaciente democracia, ganando así terreno en más ámbitos de la vida social. Esta etapa de la historia nacional se caracterizó como una salida del silencio; ya que el contexto político autoritario previo donde reinó la exclusión de toda política pública de salud reproductiva y la feroz represión generalizada de las voces que pudieran reclamar derechos, el periodo dominado por el terrorismo de estado, fue una etapa de silencio que se quebró con la vuelta a la Democracia (Pecheny y Petracci, 2006).

En este marco, y ya entrados en el Siglo XXI, se ha dado una gran ampliación en el marco normativo en temáticas como identidades sexuales, derechos sexuales y reproductivos, educación sexual integral, acciones para la erradicación de todo tipo de violencia contra la mujer y la legalización de la Interrupción Voluntaria del Embarazo a fines del año pasado. En paralelo, se sumaron movimientos sociales como el Ni Una Menos ${ }^{2}$ y la Campaña Nacional por el Aborto Legal, Seguro y Gratuito ${ }^{3}$ que con la estética del feminismo sub 18 , como el uso de "gliter", purpurina y pañuelos verdes, inundan el espacio público. A este creciente movimiento de mujeres jóvenes que se identifican con el feminismo como identidad política es que Peker (2017) denomina la revolución de las hijas.

Como se puede visualizar, los movimientos de mujeres y la ampliación de derechos en Argentina han tomado una fuerte retroalimentación y redireccionamiento en la búsqueda de igualdad entre géneros. Sin embargo, como "cientistas" sociales, nos interesa abordar distintos tipos de interrogantes con respecto a las políticas públicas existentes y aplicadas en torno a las mujeres que tengan un marco legal de referencia. Para llevar adelante el cometido, en base a un relevamiento, buscaremos dar cuenta de la jurisprudencia existente en la temática. Con tal objeto, en un primer momento, se realizará una matriz con las Leyes y Programas creados en la Argentina en relación a las mujeres durante el período 2003-2020. Desde una mirada analítica, es que nos preguntamos si esta ampliación normativa nos permite hablar de igualdad y/o transversalidad. Si estamos hablando de la mujer, en singular, o de mujeres, en plural.

El artículo se ha organizado en cuatro partes: aspectos teóricos que remite al recorrido de conceptos y discusiones en Argentina, en específico - y del contexto latinoamericano en general-, la legislación existente, y los programas que remiten a la mujer; un apartado metodológico que ahonda en explicaciones sobre el armado y técnica de datos primarios; lo que permite dar paso al análisis de situación, para luego ahondar en las reflexiones finales.

\footnotetext{
${ }^{1}$ Elsa Dorling (2009) entiende al feminismo como una tradición de pensamiento que por lo menos desde el Siglo XVII plantea, según diversas lógicas demostrativas, la igualdad entre hombres y mujeres "acorralando los prejuicios relativos a la inferioridad de las mujeres o denunciando la ignominia de su condición" (p. 13).

2 El Colectivo Ni Una Menos, con diversas expresiones por región, se consolida como un movimiento con distintos hitos organizativos como: los Encuentros Nacionales de Mujeres y en la Campaña Nacional por el Derecho al Aborto legal, seguro y gratuito. $Y$ tienen como referentes a las Madres y Abuelas de Plaza de Mayo, en las mujeres revolucionarias que fueron sus hijas, en los movimientos LGBTIQ, en las que se organizaron en sindicatos y en las piqueteras, en las mujeres migrantes, indígenas y afrodescendientes y en la larga historia de luchas por la ampliación de derechos. http://niunamenos.org.ar/quienes-somos/carta-organical

${ }^{3}$ La Campaña Nacional por el Derecho al Aborto legal, Seguro y Gratuito es una amplia y diversa alianza federal, que articula y recupera parte de la historia de las luchas desarrolladas en Argentina en pos del derecho al aborto legal, seguro y gratuito. Tiene sus simientes en el XVIII Encuentro Nacional de Mujeres realizado en Rosario en el año 2003 y en el XIX ENM desarrollado en Mendoza en el 2004. http://www.abortolegal.com.ar/
} 


\section{Aspectos teóricos}

\section{Estado, sujetos y normativas}

Como punto de partida, con el fin de sumar una perspectiva de género, nos interesa abordar los aportes de las Teorías Feministas al análisis del Estado y sus sistemas jurídicos, para así poder contar con herramientas analíticas para pensar por qué y cómo el Estado produce sujetos. Siguiendo a autoras como Fraser (1995), Haney (1998) y Rodríguez (2008) otorgan un lugar central al Estado como encargado de construir igualdad entre hombres y mujeres. Según las autoras, es el Estado quien realiza intervenciones públicas que distribuyen recursos materiales y oportunidades de reconocimiento simbólico entre los géneros. A lo que MacKinnon (1995) suma que no es cualquier tipo de Estado, sino un Estado masculino, que se caracteriza por ser sistémico, coactivo, legitimado y epistémico, en otras palabras, también lo denomina régimen.

Por otra parte, si bien Marques-Pereira (1993) sostiene que las Teorías del Estado no han integrado el concepto de género, cierto grupo de politólogas feministas pujaron en esa dirección. En este marco, el género resulta un sistema social que divide el poder, por tanto, deviene en un sistema político y las relaciones entre hombres y mujeres dentro de este son relaciones políticas (MacKinnon, 1995). Por tanto, Rodríguez sostiene, en diálogo con Acker (1990), que las políticas públicas son "generizadas", ya que las mismas incluyen en sus contenidos, metodologías y objetivos, concepciones sobre atributos culturales masculinos y femeninos, como así también, creencias sobre los comportamientos deseables para cada uno de los sexos. Al respecto la autora nos va a decir, "los hombres en las organizaciones toman su conducta y sus perspectivas para representar lo humano, las estructuras y procesos organizacionales son teorizadas como neutrales ... la visión de las organizaciones separa las estructuras de las personas en ellas" (Acker, 1990, p. 142).

Para pensar en términos de Acker (1990) es necesario concebir al género no como categoría a anexar al análisis de las organizaciones, por el contrario, la perspectiva de género tiene que ser contemplada como constituyente de la misma. Es en las mismas organizaciones, nos va a decir la autora, que existen procesos generizados ${ }^{4}$ que traen implícitos "las ventajas y desventajas, explotación y control, acción y emoción, significado e identidad cuentan con un patrón, definido en términos de la distinción entre femenino y masculino, feminidad y masculinidad" (Acker, 1990, p. 251).

Siguiendo con las líneas de Acker, los procesos de "generización" ocurren en base a 4 puntos que interactúan entre sí. El primero, la construcción de divisiones en una línea acorde al género, es decir, prácticas comunes que producen patrones generizados de trabajos, salarios, jerarquías, poder y subordinación. Éstos producen jerarquización vertical (por ejemplo, los hombres casi siempre ocupan lugares de jerarquía); jerarquización horizontal (determinadas funciones llevadas adelante casi exclusivamente por hombres o por mujeres, lo que produce la masculinización o la feminización de ciertas tareas). Segundo, la formación de imágenes y símbolos que expresan, explican y refuerzan tales divisiones. Tercero, las interacciones cara a cara entre personas de diferentes sexos que producen la dominación, afianzan la subordinación y generan exclusiones. Por último, la demanda de conductas o actitudes acordes al género de cada persona. Teniendo en cuenta los aportes de Acker (1990) se puede comprender por qué las estructuras organizativas no resultan neutras al género.

En este punto sumamos los aportes de Butler (2007) que, en base a su lectura de Foucault nos afirma que los sistemas jurídicos de poder "producen a los sujetos a los que más tarde representan" (Butler, 2007, p. 47). Para la estadounidense, las nociones jurídicas de poder regulan la esfera política en términos negativos, en otras palabras, mediante la limitación, la prohibición, la reglamentación y el control de las

\footnotetext{
${ }^{4}$ Una forma de ejemplificar los procesos generizados puede ser a través de la figura del Trabajador Abstracto. Según Acker (1990) las tareas y las funciones están descritas de manera neutral, como si fuera un lugar vacío a ser ocupado. Este trabajador sin cuerpo que solo existe para el trabajo, en palabras de la autora, "es el trabajador varón real, cuya vida se centra alrededor de su trabajo full-time y para toda la vida, mientras su esposa u otra mujer cuida sus necesidades personales y sus hijos” (Acker, 1990, 149).
} 
personas vinculadas a esa estructura política mediante la operación contingente y retractable de la elección. A pesar de lo expuesto, la autora nos advierte que los sujetos regulados por esas estructuras, ya que están sujetos a éstas, "se constituyen, se definen y se reproducen de acuerdo con las imposiciones de dichas estructuras" (Butler, 2007, p. 47).

En articulación con lo anterior, para Butler, lo que ella llama "el problema del sujeto" es primordial para la política, en particular para la política feminista, ya que los sujetos jurídicos se construyen, en sus palabras "mediante ciertas prácticas excluyentes que, una vez determinada la estructura jurídica de la política, no se perciben" (Butler, 2007, p. 47). En definitiva, para la autora,

la construcción política del sujeto se realiza con algunos objetivos legitimadores y excluyentes, y estas operaciones políticas se esconden y naturalizan mediante un análisis político en el que se basan las estructuras jurídicas. El poder jurídico produce [énfasis añadido] irremediablemente lo que afirma sólo representar; así, la política debe preocuparse por esta doble función del poder: la jurídica y la productiva. De hecho, la ley produce y posteriormente esconde la noción de un sujeto anterior a la ley [énfasis añadido] para apelar a esa formación discursiva como una premisa fundacional naturalizada que posteriormente legitima la hegemonía reguladora de esa misma ley. (Butler, 2007, pp. 47-48)

A lo ya dicho, le añadimos la postura de Mackinnon (1995), que sostiene que este Estado excluyente, impone el punto de vista masculino y no de cualquiera manera, sino como norma universal en el orden social por él instituido; como así también en los procedimientos formales que establece. Por tanto, los sistemas jurídicos producen sujetos y, además, los producen desde un punto de vista masculino. Algo más que agregar, para MacKinnon (1995) independientemente de la perspectiva del Estado, ya sea liberal o marxista, la Ley ha sido omnipotente o impotente con respecto a la mujer, la autora nos va a decir "todo o nada". Por ende, la postura feminista con relación al Estado ha sido esquizoide en cuestiones básicas para la mujer como el aborto, la violación y la discriminación sexual.

En suma, hasta el momento nos encontramos con un Estado que es el responsable de construir igualdad entre los géneros, sin embargo, es un Estado que tiene un punto de vista masculino. En este marco, el género es un sistema político y las políticas públicas de éste derivadas son generizadas, es decir que incluyen en sus concepciones comportamientos deseables para los sexos. A su vez, los sistemas jurídicos producen sujetos de una manera particular: la exclusión. Y los Estados, independientemente de su perspectiva, han actuado a todo o nada con la mujer. En el próximo apartado, teniendo en cuenta cómo se producen sujetos desde un Estado masculino, nos proponemos pensar el contexto argentino, para poder sumar al análisis los conceptos de integralidad y corresponsabilidad para pensar a un conjunto particular de Leyes y Programas desde una perspectiva de género.

\section{Contexto Argentino, Mujeres, Integralidad y Corresponsabilidad}

El estallido social del año 2001 marcó un final para el modelo de acumulación instalado en Argentina en 1976, con la dictadura cívico militar (Arias, 2012). "Corralito", saqueos a supermercados y cortes de rutas sirvieron como corolario de un periodo caracterizado por la valorización financiera, la privatización de empresas públicas, la reforma de los sistemas de seguridad social, aumento de la desocupación, pobreza e indigencia, entre otros (Basualdo, 2008).

A partir del año 2003, en un contexto de cambio social y político, marcado por una gran presencia estatal en la mejora de la calidad de vida de la población, a partir de una serie de modificaciones estructurales en Argentina comienza una etapa de ampliación de derechos y aumento de la equidad social. Desde el ejecutivo, se diseñaron e implementaron políticas públicas y programas sociales, al mismo tiempo que se acompañaron el cumplimiento de leyes para el ejercicio pleno de los derechos de los sectores más postergados. 
Teniendo en cuenta lo mencionado en el informe, en articulación con el análisis de Pecheny (2014) puede decirse que, desde comienzos del último siglo, ha existido un gran avance en relación a derechos sexuales y reproductivos, entendidos como "una reivindicación de una verdadera igualdad entre las ciudadanas y los ciudadanos, puesto que la libre disposición del propio cuerpo es una condición de la plena autonomía de los individuos sexuados" (Pecheny, 2014, p. 7). Si nos ponemos a observar en qué derechos sí se ha avanzado, podemos nombrar los siguientes: el reconocimiento de la sexualidad, independientemente de la reproducción (mediante el acceso a educación sexual, el acceso a la anticoncepción y recientemente el acceso a la interrupción voluntaria del embarazo); la reproducción por fuera del vínculo heterosexual (por la fertilización asistida y el derecho de adopción a parejas homosexuales); así como también el reconocimiento por parte del Estado de diversos modos sexoafectivos de relacionarse con la proclama de la Ley de Matrimonio Igualitario; a lo que se añade la ruptura con la estructura binaria del género/sexo con la Ley de Identidad Trans (Pecheny, 2014).

En particular, y para los fines de este artículo, en este periodo, desde el Congreso de la Nación se sancionaron un conjunto de Leyes que resultaron más que relevantes para la situación de las mujeres en el país. El devenir de éstas fue variando. El caso de la Ley $\mathrm{N}^{\circ} 26.618$ Matrimonio Igualitario (2010) y la Ley $\mathrm{N}^{\circ} 26.743$ Identidad de Género (2012) contaban con fuerte apoyo desde el Poder Ejecutivo y en ambas cámaras del recinto. Por otra parte, la Ley №26.618 Protección Integral para Prevenir, Sancionar y Erradicar la Violencia contra las Mujeres en los Ámbitos en que desarrollen sus relaciones interpersonales (2009) y la Ley $\mathrm{N}^{\circ} 26.150$ Educación Sexual Integral (2006) encontraron apoyo en varios sectores del arco político y se instrumentaron a partir de diversos programas.

También nos encontramos con la Asignación Universal por Hijo que tiene un recorrido peculiar. En un primer momento surge a partir de un Decreto 1602 del año 2009 para luego después, en el año 2012, debido a la fuerza y legitimidad que ganó en la sociedad ser aprobada en el Congreso como una modificación a la Ley №24.714 Regímenes de Asignaciones Familiares.

Un caso que nos resulta de suma importancia en la vida social, política y cultural de nuestro país es la Ley $N^{\circ} 27.610$ Acceso a la Interrupción Voluntaria del Embarazo (2020), que nace como propuestas sucesivas que se realizaron desde la Sociedad Civil (a partir de la Campaña Nacional por el Derecho al Aborto Legal, Seguro y Gratuito y luego de varias presentaciones y debates parlamentarios que movilizaron a la sociedad toda) se convirtió en Ley a fines del 2020 durante la pandemia.

Este gran marco normativo crea distintos tipos de "sujetos mujer" que resulta útil pensar en un marco de ampliación de derechos, pero así también desde una visión con perspectiva de género con el fin de responder interrogantes tales como ¿Qué tipo de sujeto mujer o sujetos mujeres promovieron estos marcos normativos?

Partido de lo más general, toda persona que se auto perciba de sexo/género femenino (Ley Identidad de Género, 2012), que haya nacido en suelo argentino, o se haya nacionalizado, es considerada sujeto mujer. Luego, vendrán las especificidades al interior de esta gran concepción; preservar su vida (Protección Integral contra violencia, 2009), interrupción embarazo (IVE/ILE, 2020), igual condición según género y estado civil (Matrimonio Igualitario, 2010), prevenir el embarazo adolescente (Plan Enia, 2017), igual condición según nivel de escolaridad (Educación Sexual Integral, 2006), asegurar culminación estudios (Plan FinES, 2007), si cuenta con hijos/as (asignación universal por hijo y por embarazo, 2009; asignaciones familiares, 2012), trabajar, formarse, capacitarse y terminar estudios primarios y/o secundarios (Programa Ellas Hacen, 2013).

En este sentido, resulta menester destacar el avance en la ampliación de derechos poniendo la mirada en el principio de igualdad entre hombres y mujeres, entendiendo a la misma como "una de las principales bases comprensivas del principio de igualdad y es punto de partida para su aplicabilidad, pero eso no basta; la igualdad debe concretarse en los hechos para ser igualdad real, no solo nominal" (García, 2008, p. 52). 
Con el fin de concretizar el principio ético, jurídico y político como el de la "igualdad" en contextos donde las personas son objeto de discriminaciones y reinan las desigualdades sociales, culturales y políticas y económicas, se requiere la creación de instrumentos que traduzcan el principio anteriormente nombrando a normativas y acciones concretas, que sean comprensibles y aplicables en la gestión administrativa del Estado. Esto es un aporte importante en lo que hace al enriquecimiento de la terminología en torno a la igualdad, sobre todo en políticas públicas (García, 2008).

En línea con lo mencionado anteriormente, en este trabajo nos proponemos analizar el marco normativo en el que se inscriben las políticas públicas destinadas a mujeres en Argentina desde el año 2003 hasta la actualidad. Pero antes, debemos precisar algunos conceptos centrales en lo que hace a estas intervenciones estatales, estos son la integralidad y la corresponsabilidad. Estos principios orientadores del accionar de los gobiernos en materia de políticas públicas, permite recuperar la perspectiva de derechos humanos que guía muchas de las legislaciones y normativas vigentes, dejando en manos del Estado la posibilidad de creación de igualdad de oportunidades.

La integralidad supone pensar en las políticas y programas, es decir la oferta programática, como así también en los sujetos/destinatarios y la demanda. En cuanto a la oferta, este principio hace referencia a la participación de los diferentes sectores del Estado de manera integral y, a la vez de diferentes niveles administrativos de gobierno (nacionales, provinciales y municipales), a fin de evitar acciones fragmentadas y/o superpuestas. En el caso de la demanda, la integralidad supone que las intervenciones contemplan todas las dimensiones de la vida y desarrollo de los sujetos, atendiendo a las problemáticas en su complejidad (Cecchini y Martínez, 2011).

Por otro lado, el principio de corresponsabilidad refiere a las responsabilidades de cada uno de los actores involucrados en el proceso de diseño e implementación de las políticas. En ese sentido

cada actor tiene capacidades y restricciones de tipo de políticas, económicas y organizacionales. Todos los actores tienen un marco de reglas que definen sus obligaciones y responsabilidades, las cuales en forma compartida generan un sistema de corresponsabilidad. El conjunto de interacciones que se encuentran y fluyen en torno a corresponsabilidades que tienen todos los actores es el que permite hablar de sistema. (Stuchilk, 2012, p. 101)

Volviendo al marco normativo mencionado más arriba, podemos afirmar que su aplicación significó un avance importante -aunque aún insuficiente - en materia de igualdad de género dando respuestas clave a la discriminación de las mujeres en todos los ámbitos de la vida. A continuación, se presenta una serie de normativas que hacen a la evolución de las políticas de igualdad que van desde beneficios sociales y económicos hasta políticas transversales de género.

\section{Metodología}

La decisión de hacer un trabajo de búsqueda de legislación vigente, remite a comenzar a responder con datos agregados cómo y cuáles han sido las respuestas que el Estado argentino dio a lo largo de ese período en materia de políticas públicas orientadas a la atención de las mujeres, en particular las mujeres jóvenes de sectores vulnerables.

Para llevar adelante este cometido, seguimos la propuesta de Aguilar, Glozman, Grondona y Haidar (2014) en su postura de discutir la consideración que se hace del corpus como una "disposición articulada de documentos" (Aguilar et al., 2014, p. 1) - con el fin de re pensar la conformación del mismo como práctica constitutiva del qué hacer investigativo. Siguiendo lo planteado por las autoras argentinas, tenemos como premisa "desnaturalizar" las unidades "dadas de antemano" (por ejemplo, todas las leyes que nombren a las mujeres) con el fin de realizar una construcción crítica y atenta de la matriz. Para esto, introducimos a la problematización como modo de realizar la investigación social. 
En este sentido y para ahondar el interrogante en torno a las políticas públicas existentes aplicadas en torno a las mujeres, se tomó la decisión metodológica de armar una matriz, la cual resume el rastrillaje hecho acerca de leyes, decretos y resoluciones existentes en la Argentina que tengan como objeto directo o indirecto a las mujeres jóvenes durante el período 2003-2020.

La matriz sintetiza, y es el punto de inicio de este trabajo para responder, a partir de la normativa vigente, en materia de protección y ampliación de derechos desde el año 2003, qué sucede con ellas.

Los criterios para ordenar la matriz han sido: El año de promulgación, el número de la ley/ decreto, la denominación o título de la misma, también se ha asociado la ley y/o decreto con algún programa/ política, de nivel nacional, que la ley haya motivado, reglamentado y/o originado. Por último, se rastreó el área de ejecución.

\section{Tabla 1}

Matriz del Marco normativo orientado a las mujeres en Argentina. Años 2003-2020

\begin{tabular}{|c|c|c|c|c|}
\hline Año & Ley/Decreto/Resolución & Denominación & Política/programa nacional & Área de ejecución \\
\hline 2003 & Ley $25.673^{\mathrm{a}}$ & $\begin{array}{l}\text { Creación del Programa } \\
\text { Nacional de Salud Sexual y } \\
\text { Procreación Responsable }\end{array}$ & $\begin{array}{l}\text { Programa Nacional de Salud } \\
\text { Sexual y Procreación } \\
\text { Responsable }\end{array}$ & Min. Salud \\
\hline 2006 & Ley 26.150 & Educación Sexual Integral & $\begin{array}{l}\text { Programa de Salud Sexual } \\
\text { Integral en la Adolescencia }\end{array}$ & $\begin{array}{l}\text { Min. Educación, Ciencia } \\
\text { y Tecnología }\end{array}$ \\
\hline 2008 & Res. 22/07 & $\begin{array}{l}\text { Plan de Finalización de } \\
\text { Estudios Primario y } \\
\text { Secundarios }\end{array}$ & $\begin{array}{l}\text { Plan de Finalización de } \\
\text { Estudios Primario y } \\
\text { Secundarios }\end{array}$ & Min. de Educación \\
\hline 2009 & Decreto $1602 / 09^{b}$ & $\begin{array}{l}\text { Asignación Universal por } \\
\text { Hijo }\end{array}$ & Asignación Universal por Hijo & ANSESC \\
\hline 2009 & Ley 26.485 & $\begin{array}{l}\text { Protección Integral para } \\
\text { Prevenir, Sancionar y } \\
\text { Erradicar la Violencia contra } \\
\text { las Mujeres en los Ámbitos } \\
\text { en que Desarrollen sus } \\
\text { Relaciones Interpersonales }\end{array}$ & $\begin{array}{l}\text { Política para prevenir y } \\
\text { erradicar la violencia contra } \\
\text { las mujeres }\end{array}$ & $\begin{array}{l}\text { Reglamentada mediante } \\
\text { el Decreto } 1011^{\mathrm{d}}\end{array}$ \\
\hline 2010 & Ley 26.618 & Matrimonio igualitario & $\begin{array}{l}\text { Política que propone igualar } \\
\text { derechos entre contrayentes } \\
\text { independientemente de su } \\
\text { sexo/género }\end{array}$ & $\begin{array}{l}\text { Poder ejecutivo } \\
\text { junto con } \\
\text { representantes de las } \\
\text { organizaciones LGBTe }\end{array}$ \\
\hline 2011 & Decreto $446 / 11^{f}$ & $\begin{array}{l}\text { Asignación Universal por } \\
\text { Embarazo }\end{array}$ & $\begin{array}{l}\text { Asignación Universal por } \\
\text { Embarazo }\end{array}$ & ANSES \\
\hline 2012 & Ley 26.743 & Identidad de género & $\begin{array}{l}\text { El INADI }{ }^{\text {h }} \text { dicta cursos de } \\
\text { capacitación al público en } \\
\text { gral. cuenta con el Taller } \\
\text { "Tejiendo Matria"i Impulsa la } \\
\text { Ley de Cupo travesti-trans' }\end{array}$ & $\begin{array}{l}\text { Poder Legislativo } \\
\text { (Cámara de } \\
\text { Diputadas/os y } \\
\text { Senadoras/es) }\end{array}$ \\
\hline 2013 & Res. 2176/13 & Ellas Hacen & Programa Ellas Haceng & Min. Desarrollo Social \\
\hline 2017 & $\begin{array}{l}\text { Resolución CFE } \\
\mathrm{N}^{\circ} 322 / 17\end{array}$ & Plan ENIAk & $\begin{array}{l}\text { Plan Nacional para la } \\
\text { Prevención del Embarazo no } \\
\text { Intencional en la Adolescencia }\end{array}$ & $\begin{array}{l}\text { Min. Educación } \\
\text { y Deporte }\end{array}$ \\
\hline 2017 & Ley 27.364 & Egreso & $\begin{array}{l}\text { Programa de } \\
\text { acompañamiento para el } \\
\text { egreso de jóvenes sin } \\
\text { cuidados parentales }\end{array}$ & Min. de Educación \\
\hline 2020 & Ley 27.610 & $\begin{array}{l}\text { Interrupción Voluntaria del } \\
\text { Embarazo - IVEI }\end{array}$ & $\begin{array}{l}\text { Presentado por primera vez } \\
\text { en el año } 2006 \text { por la campaña } \\
\text { nacional por el derecho al } \\
\text { aborto legal, seguro y gratuito }\end{array}$ & $\begin{array}{l}\text { Poder legislativo } \\
\text { (cámara de diputadas/os } \\
\text { y senadoras/es) }\end{array}$ \\
\hline 2020 & Ley 27.611 & $\begin{array}{l}\text { Atención y cuidado integral de } \\
\text { la salud durante el embarazo y } \\
\text { la primera infancia }\end{array}$ & Plan Nacional de los Mil días & ANSES \\
\hline
\end{tabular}




\begin{tabular}{|c|c|c|c|c|c|}
\hline Año & Ley/Decreto/Resolución & Denomina & ión & Política/programa nacional & Área de ejecución \\
\hline 2020 & Decreto $734 / 2020$ & $\begin{array}{l}\text { Creación del } \\
\text { Acompañamiento }\end{array}$ & Programa & $\begin{array}{l}\text { En el marco del Plan Nacional } \\
\text { de Acción contra: las Violencias } \\
2020-2022\end{array}$ & $\begin{array}{l}\text { Ministerio de las } \\
\text { Mujeres, Géneros y } \\
\text { Diversidad y ANSES }\end{array}$ \\
\hline
\end{tabular}

\footnotetext{
a Si bien la ley se sancionó en el año 2002, el programa comenzó a regir desde 2003, este es el primer programa que consideramos del período analizado.

${ }^{b}$ En 2011 se incorporó a Ley de Régimen de Asignaciones Familiares N²4.714

c La Administración Nacional de la Seguridad Social (de ahora en más ANSES) es un organismo descentralizado, creado en el año 1991, que tiene a su cargo la administración de las prestaciones y los servicios nacionales de la Seguridad Social en la República Argentina. Para más información ver: https://www.anses.gob.ar/institucional [14/12/2021].

d En los años siguientes, las provincias aprobaron normas locales de adhesión al texto de la norma adaptándola.

e Las siglas refieren a Lesbianas, Gais, Bisexuales y Transgénero.

${ }^{f}$ Ese mismo año se incorporó a Ley de Régimen de Asignaciones Familiares N²4.714

g A partir del 2018 se fusiona con el programa Argentina Trabaja y conforman el programa "Hacemos Futuro".

h El Instituto Nacional contra la Discriminación, la Xenofobia y el Racismo (INADI) es un organismo nacional cuyo fin es eliminar la discriminación en todas sus formas.

¡ (Herramientas referidas a la participación y la prevención de la violencia política contra las mujeres y LGBTI+ por motivos de Género)

¡A la fecha (junio 2021), cuenta con media sanción en la Cámara de diputados y se debate en la Cámara de Senadores.

k Plan Nacional de Prevención del Embarazo No Intencional en la Adolescencia.

' Proyecto de ley llevado a cabo por la Campaña Nacional por el Derecho al Aborto Legal, Seguro y Gratuito en el año 2006, que fue rechazado en 2018.
}

\section{Resultados}

\section{Análisis de situación}

Resulta menester tener un paso previo al análisis de la tabla 1, y es el que refiere a dar cuenta del contexto latinoamericano (Suramérica, sobre todo), para luego entender y contextualizar a la Argentina. Se presentan los casos de Brasil y Chile a modo de ejemplo (y antecedentes) de países que implementaron políticas públicas con importante cobertura y sostenibilidad a lo largo del tiempo. Estos casos, pioneros en la región, sentaron precedentes para el surgimiento de la AUH en Argentina en materia de políticas redistributivas ampliando derechos sociales y reduciendo las brechas en los niveles de ingresos de sus poblaciones. En línea con lo propuesto, Mesa-Lago (2004), establece una clasificación de los países de América Latina centrando la distinción de acuerdo con el momento de inicio de sus sistemas de seguridad o protección social y el grado de desarrollo de los mismos. Este criterio le permite señalar tres tipos o grupos de países: "pionero-alto" en el que incluye a Argentina, Cuba Chile, Brasil, Costa Rica y Uruguay; “intermedio" integrado por, Bolivia, Colombia, Ecuador, México, Panamá, Perú y Venezuela. Finalmente, el “tardío-bajo" compuesto por El Salvador, Guatemala, Haití, Honduras, Nicaragua, Paraguay y República Dominicana.

Chile en el año 2002, aplica el Sistema "Chile Solidario", el cual ha sido una de las principales herramientas en la lucha contra la pobreza desde sus orígenes, comenzó focalizado en la extrema pobreza, y se ha ido ampliando paulatinamente (tanto en cobertura como alcance). El sistema se compone de cuatro programas complementarios: "Puente", "Vínculos", "Calle" y "Caminos", todos programas de asistencia monetaria que se destacan por un alto grado de condicionalidad y un fuerte involucramiento por parte del Estado en la situación de los hogares.

Un segundo antecedente es Brasil, que, en el año 2004, llevó a cabo el Plan Bolsa Familia, el cual se implementó y constituyó como principal programa de asistencia social. La magnitud del plan es 
considerable, puesto que el mismo alcanza al 23\% de los 190 millones de personas que habitan el país. El programa consiste básicamente en una transferencia de ingresos no condicionados a sectores de bajos ingresos, favoreciendo especialmente a los hogares que cuenten con la presencia de niños. El único requisito para acceder es que los niños se encuentren en edad escolar y cumplan con los planes de vacunación obligatorio. El programa es cofinanciado por el Banco Mundial, institución que ha destacado los éxitos del mismo en materia de combate contra la pobreza extrema y la garantía del cumplimiento de derechos sociales básicos (principalmente salud y educación). Los requisitos para acceder al plan se estipulan en función del ingreso del hogar. La condición de acceso vía un ingreso máximo implica que el programa no tiene un carácter universal, sino que el mismo se encuentra deliberadamente orientado a un sector específico de la población.

El tercer antecedente que puede mencionarse es el Programa Juntos, de Perú. Luego de analizar experiencias de programas similares en países como Brasil, México, Chile y Honduras, Perú lanza el programa en el año 2005. Como menciona Agis et al. (2013), debido a que el país posee una situación de desigualdad extrema y una pirámide poblacional fuertemente desbalanceada a favor de estratos de baja edad, se resolvió concentrar la asistencia monetaria en familias con menores de 14 (catorce) años de edad.

Respecto de la Argentina existen leyes en relación a la mujer antes del año 2002, como la Ley №13.010, que refiere al sufragio femenino, así como la Ley $N^{\circ} 24.417$ que remite a la protección contra la violencia familiar. Estas leyes, antecedentes y muy importantes en nuestra legislación y marco de referencia, no terminan de reflejar a la sujeta de derechos a la que se quiere hacer referencia en este trabajo.

El recorte de años (2003-2020), remite justamente a poder pensar a la mujer joven, aquella que resulta beneficiaria de las políticas públicas que han sido nombradas en la tabla 1. Son estas leyes y programas mencionadas, las que convergen de manera transversal y multidimensional (aquí se consideran las dimensiones salud - sexualidad - educación y violencia) en la Argentina de los últimos años en calidad de políticas públicas, leído en clave de mejoramiento de la calidad de vida de la población en general, y de la mujer joven en particular.

Es a partir de esta vinculación de dimensiones que la sujeta/beneficiaria de las políticas pensadas e implementadas marcan un punto de quiebre (y ampliación de derechos), en relación a la legislación preexistente (que refiere a un periodo anterior al 2003). Como se menciona en la introducción, a partir del año 2003 en la Argentina comienza a darse un contexto de cambio social y político, marcado por una gran presencia estatal en la mejora de la calidad de vida de la población, a partir de ampliación de derechos y aumento de la equidad social.

De la tabla 1 realizada, se observa que las leyes sancionadas, así como los decretos y resoluciones ministeriales, buscan en primera instancia ampliar derechos y garantías constitucionales para las mujeres, así como en la gran mayoría estuvieron acompañados de políticas y programas que buscan garantizar su cumplimiento mediante acciones y dispositivos concretos. Para ello diferentes órganos del estado nacional, en primera instancia los diferentes ministerios (como ser Ministerio de las Mujeres, Géneros y Diversidad), más luego las secretarías, y subsecretarías, o bien entidades como la ANSES revisten del poder para hacer valer y garantizar el cumplimiento, cada entidad a partir de diferentes dispositivos y disposiciones.

El punto inicial de este trabajo, de este interrogante que se busca responder, comienza en el año 2002, cuando se sanciona la ley que da origen al Programa Nacional de Salud Sexual y Procreación Responsable, cuya área de ejecución (hoy día), corresponde al Ministerio de Salud de la Nación. Con el objetivo de promover la igualdad de derechos y acceso a la atención integral de la salud sexual y salud reproductiva, se suma el Ministerio de Educación como ente de control de dicha ley.

En el año 2006 se sanciona la ley de Educación Sexual Integral, la cual tiene entre sus objetivos el dictado de talleres sobre la educación sexual integral, siendo su área de aplicación todas las escuelas del 
territorio argentino. Ambas legislaciones (la del 2002 y 2006), serán recuperadas en el año 2017 en el Plan ENIA, que tiene entre sus máximas la prevención del embarazo no intencional en la adolescencia, creado mediante una resolución del Ministerio de Educación (al día de hoy el plan depende del ministerio de salud, aunque se encuentra en diálogo constante con el de educación).

En el período analizado también se sancionaron leyes y dictaron resoluciones que otorgan competencias y obligaciones en materia de derechos para las personas desde el ministerio de Educación, como ser la Resolución 22/07 que da origen al Plan de Finalización de Estudios Primarios y Secundarios. A diferencia de los programas que se desprenden de las leyes mencionadas anteriormente, este programa supone una transferencia de dinero mensual a adolescentes y jóvenes que no hayan finalizado sus estudios primario o secundario y quieran hacerlo. Si bien estas acciones no son destinadas específicamente a las mujeres, parte de la población destinataria son mujeres (adolescente y jóvenes en este caso).

Por su parte, la Asignación Universal por Hijo y la Asignación Universal por Embarazo (DNU 1602/09 y 446/11 respectivamente) habían sido políticas que desde sus orígenes generaron modificaciones estructurales en las condiciones de vida de las mujeres (y sus hijas/os). La misma, consta de una transferencia de ingresos por parte del Estado a los hogares que se encontraban por fuera del mercado de trabajo formal. Las beneficiarias de esta asignación son las madres. En el 2020, se sanciona la ley de Interrupción voluntaria del embarazo cerrando un ciclo de avances y luchas en materia de salud sexual y reproductiva y, sobre todo, ampliación de derechos para las mujeres; y en simultáneo, se sanciona la ley de los Mil días que supone la transferencia monetaria para la atención y cuidado integral de la salud durante el embarazo y la primera infancia.

Si bien la Ley $\mathrm{N}^{\circ} 27.364$ de Egreso sancionada en 2017 tampoco se enfoca específicamente a las mujeres, su aplicación supone una beca mensual y el acompañamiento a adolescentes y jóvenes que se encuentren sin cuidados parentales al momento de salir de una institución de cuidado formal. En la misma línea, las leyes de matrimonio igualitario y la de identidad de género (26.681 y 26.743 respectivamente) dan cuenta de un avance en materia de igualdad y ampliación de derechos entre las personas.

Por último, en el año 2009 se sanciona la Ley de Protección Integral para prevenir, sancionar y erradicar la violencia contra las mujeres en los ámbitos en que desarrollen sus relaciones interpersonales, sin embargo, es en 2020 a partir del decreto 734/2020, en el marco del Plan Nacional de Acción contra las Violencias, que dicha iniciativa comienza a tomar protagonismo en la esfera pública a partir del Plan de Acompañamiento a mujeres víctimas de hechos de violencia.

En este punto resulta importante destacar que todos los planes, políticas, leyes y decretos mencionados, tienen algún tipo de triangulación y/o cuentan con la participación del Ministerio de Desarrollo Social, en calidad de efector de las decisiones, como ente regulador de los recursos económicos, o bien como gestor de agenda.

En el caso del Ministerio de Trabajo, si bien cuenta con algunos programas de capacitación laboral, no cuenta con la misma presencia y poder de ejecución que el ministerio de desarrollo social. Tal así son las cosas que al menos resulta llamativo para las autoras, que desde este ministerio (el de trabajo), no se ejecuten programas que tengan a las mujeres como principales destinatarias, y que no tengan vínculo o como se indicara, algún tipo de triangulación, y ayuda de cualquier tipo del ministerio de desarrollo social (un claro ejemplo es el programa Ellas Hacen, destinado a mujeres, para que puedan trabajar y mejorar sus barrios, capacitarse, y terminar sus estudios, sean estos de nivel primario y/o secundario). Lo cual hace, al menos, dudar de la ampliación de derechos de las mujeres en lo que al ámbito laboral y mercado de trabajo refiere. Este punto es parte de un trabajo que las autoras vienen trabajando en otros espacios y se espera su pronta publicación, por ello aquí se menciona la complejidad y problemática pero no se ahonda. 


\section{Conclusiones}

Este trabajo buscó dar cuenta de las legislaciones vigentes, en calidad de leyes, decretos, resoluciones ministeriales, programas y políticas públicas, en un contexto de años que van del 2003 al 2020, a lo largo de todo este período de tiempo se ha podido vislumbrar el avance en políticas de inclusión social de la sociedad toda, y el de las mujeres con algunas limitaciones, y aquí es donde se quiere poner énfasis: han pasado 17 años desde esa primera sanción de ley que buscaba hacer foco en la atención de las mujeres jóvenes. En ese llamado a considerarlas dentro de la agenda gubernamental, vemos la presencia de organismos estatales como los ministerios de salud, educación, el de desarrollo social, y el de mujeres y género (recientemente creado), dando cuenta del esfuerzo por construir políticas públicas con un enfoque transversal y multidimensional, tal como se menciona (salud, sexualidad, educación y violencia). Sin embargo, estas iniciativas se consideran insuficientes si de igualdad se trata. Se observa que la atención hacia esta población se basa en políticas asistenciales y de protección social que perpetúan el rol social de las mujeres (es especial las más jóvenes y de menores recursos) en tanto responsables de la reproducción de la vida, pero no se avanza en políticas vinculadas al mercado de trabajo formal que permitan un abordaje integral de las problemáticas que atraviesan como resultado de las desigualdades de clase y género, baste mencionar "piso pegajoso" y "techo de cristal”. El día en que se esté más cerca de romper con estos bloqueos para el ingreso al mercado de trabajo, podrá pensarse realmente en políticas de equidad que en su formulación contemplen y tiendan a reducir la disparidad de género en las tareas domésticas y de cuidado.

Así todo, y en contexto de pandemia, no puede dejar de mencionarse que Argentina es, dentro del continente un país que cuenta en su haber con una larga trayectoria de voluntad política con orientación pionera en ampliación de derechos, elevando la vara para el resto de los países de la región y el mundo, pero sobre todo para las mujeres. Ejemplo de ello han sido las últimas leyes sancionadas en el país, la Ley 27.610 Interrupción Voluntaria del Embarazo (IVE), y el Decreto 721/2020 (ley de cupo trans), que no son sino reflejo y consecuencia de la trayectoria que aquí se ha buscado plasmar. Sin embargo, aún queda mucho más camino por recorrer, y este trabajo busca dar cuenta y ser una señal de alerta de las vacancias que aún existen materia de equidad de género y de lo frágiles que son las mujeres más jóvenes y empobrecidas, de ingresar y permanecer en el mercado de trabajo.

\section{Referencias}

Acker, J. (1990). Hierarchies, jobs, bodies: A Theory of Gendered Organizations. Gender \& Society, 4(2), 139-158. https://doi.org/10.1177/089124390004002002

Agis E., Cañete C., y Panigo D. (2013) El impacto de la asignación universal por hijo en Argentina. El impacto de la asignación universal por hijo en Argentina. presentación formal de los resultados anticipados en 2010. Empleo, desempleo y políticas de empleo, $15, \quad$ 1-77. https://ri.conicet.gov.ar/handle/11336/17814

Aguilar, P. L., Glozman, M., Grondona, A., y Haidar, V. (2014). ¿Qué es un corpus? Revista de la Carrera de Sociología, $\quad 4(4), \quad 35-64$. https://publicaciones.sociales.uba.ar/index.php/entramadosyperspectivas/article/view/527

Arias, A. J. (2012). Pobreza y modelos de intervención: aportes para la superación del modelo de asistencia y promoción. Espacio Editorial.

Basualdo, E. (2008). La distribución del ingreso en la Argentina y sus condicionantes estructurales. Memoria Anual, 307-326. https://www.cels.org.ar/web/capitulos/la-distribucion-del-ingreso-en-laargentina-y-sus-condicionantes-estructurales/

Butler, J. (2007). El género en disputa: el feminismo y la subversión de la identidad. Paidós.

Cecchini S., y Martínez, M. (2011). Protección social inclusiva en América Latina. Una mirada integral, un enfoque de derechos. CEPAL. 
Decreto 1602 de 2009. Incorporase el Subsistema no Contributivo de Asignación Universal por hijo para $\begin{array}{llllll}\text { Protección } & \text { Social. } & 29 & \text { de } & \text { octubre } & \end{array}$ http://servicios.infoleg.gob.ar/infoleglnternet/anexos/155000-159999/159466/norma.htm

Decreto 446 de 2011. Modificase la Ley $N^{\circ} 24.714$ en relación con la Asignación por Embarazo para Protección Social. 19 de abril de 2011. https://www.argentina.gob.ar/normativa/nacional/decreto446-2011-181250

Decreto 734 de 2020. Programa de apoyo y acompañamiento a personas en situación de riesgo por violencia de género por violencia por razones de género - ACOMPAÑAR. DCTO-2020-734-APN-PTE. 8 de septiembre 2020. https://www.boletinoficial.gob.ar/detalleAviso/primera/234705/20200909

Di Marco, G. (2010). Los movimientos de mujeres en la Argentina y la emergencia del pueblo feminista. La aljaba, 14, 51-67. http://www.biblioteca.unlpam.edu.ar/pubpdf/aljaba/v14a03dimarco.pdf

Dorlin, E. (2009) Sexo, Género y Sexualidades. Introducción a la teoría feminista. Nueva Visión.

Fraser, N. (1995). Recognition or redistribution? A critical reading of Iris Young's Justice and the Politics of Difference. Journal of Political Philosophy, 3(2), 166-180. https://doi.org/10.1111/j.14679760.1995.tboo033.x

García, E. (2008). Políticas de igualdad, equidad y gender mainstreaming. ¿De qué estamos hablando? Marco conceptual. PNUD. https://atlasdegenero-semujeres.edomex.gob.mx/sites/atlasdegenerosemujeres.edomex.gob.mx/files/files/2\%20Pol\%C3\%ADticas\%20de\%20igualdad.pdf

Haney, L. A. (1998). Engendering the Welfare State. A review article. Comparative Studies in Society and History, 40(4), 748-767. doi:10.1017/S0010417598001728

Ley 25.673 de 2003. Creación del Programa Nacional de Salud Sexual y Procreación Responsable. Exp D2178-03.

https://www.argentina.gob.ar/sites/default/files/ley_25673_decretos_declaracion_de_repudio.p df

Ley 26.150 de 2006. de Educación Sexual Integral. https://identidadydiversidad.adc.org.ar/normativa/ley26-150-de-educacion-sexual-integral-2006-2009/

Ley 26.485 de 2009. de Protección Integral para Prevenir, Sancionar y Erradicar la Violencia contra las Mujeres en los Ámbitos en que desarrollen sus relaciones interpersonales. Abril 1 de 2009. http://servicios.infoleg.gob.ar/infolegInternet/anexos/150000-154999/152155/norma.htm

Ley 26.618 de 2010. Matrimonio Igualitario. Boletín Oficial, 21. https://www.acnur.org/fileadmin/Documentos/BDL/2017/10957.pdf

Ley 26.743 de 2012. de Identidad de Género. http://www.jus.gob.ar/media/3108867/ley_26743_identidad_de_genero.pdf

Ley 27.364 de 2017. Programa de Acompañamiento para el egreso de jóvenes sin cuidados parentales. http://servicios.infoleg.gob.ar/infolegInternet/anexos/275000-279999/276156/norma.htm

Ley 27.610 de 2020. Acceso a la Interrupción Voluntaria del Embarazo. http://servicios.infoleg.gob.ar/infolegInternet/verNorma.do?id=346231

Ley 27.611 de 2020. Ley Nacional de Atención y Cuidado integral de la salud durante el embarazo y la primera infancia. http://servicios.infoleg.gob.ar/infolegInternet/verNorma.do?id=346233

MacKinnon, C. A. (1995). Hacia una teoría feminista del Estado. (Martín, E., Trad.). Ediciones Cátedra.

Marques-Pereira, B. (1993). Estado y Estado benefactor: metodologías feministas. Revista Mexicana de sociología, 55(3) 121-131. https://doi.org/10.2307/3540925

Mesa-Lago, C. (2004). Evaluación de un cuarto de siglo de reformas estructurales de pensiones en América Latina. Revista de la CEPAL, 84.

Pecheny, M. (2014). Derechos humanos y sexualidad: hacia la democratización de los vínculos afectivos en la Argentina. Sudamérica: Revista de Ciencias Sociales, (3), 119-136.

Pecheny, M., y Petracci, M. (2006). Derechos humanos y sexualidad en la Argentina. Horizontes antropológicos, 12(26), 43-69.

Peker, L. (2017). La revolución de las mujeres: no era sólo una píldora. Eduvim. 
Rodríguez, A. L. (2008). Las políticas sensibles al género: variedades conceptuales y desafíos de intervención. Temas y debates: revista universitaria de ciencias sociales, 12(16), 109-130.

Resolución 22/07 de 2008 [Ministerio de Educación de Argentina]. Plan de Finalización de Estudios Primarios y Secundarios - Ministerio de Educación. http://www.infoleg.gob.ar/basehome/actos_gobierno/actosdegobierno22-9-2008-1.htm

Resolución 2176 de 2013 [Ministerio de Desarrollo Social de Argentina]. Programa de Ingreso Social con Trabajo - línea programática "Ellas Hacen". 14 de marzo de 2013.

Resolución CFE N³22 de 2017 [Ministerio de Educación y Deporte de Argentina]. Plan Nacional de Prevención del Embarazo No Intencional en la Adolescencia (ENIA). 21 de junio de 20017. http://www.bnm.me.gov.ar/giga1/normas/RCFE_322-17.pdf

\section{Nota de Autor}

La información presentada en este artículo sobre el marco normativo y las políticas públicas en Argentina es parte de la tesis de una de las autoras de este trabajo, para optar por el título de Magíster en Intervención Social de la Universidad de Buenos Aires. No existe ningún conflicto de intereses que revelar. 